\title{
Large inflammatory fibroid polyp of cardia managed laparoscopically - a case report and review of the literature
}

\author{
Andrzej P. Kwiatkowski, Krzysztof Paśnik \\ Department of General, Oncological, Metabolic and Thoracic Surgery, Military Institute of Medicine, Warsaw, Poland
}

Videosurgery Miniinv 2014; 9 (4): 623-626

DOI: $10.5114 /$ wiitm.2014.46448

\begin{abstract}
Inflammatory fibroid polyp or Vanek's tumor of the gastrointestinal tract is a rare, benign neoplasm. The lesion may occur at any age but is commonest in the sixth and seventh decades and is more often found in women. It is mostly situated in the stomach, especially in the antrum. Symptoms depend on the location and the size of the lesion. We present a case of a 67-year-old woman with a large inflammatory polyp of the cardia with a diameter of $10 \mathrm{~cm} \times$ $5.5 \mathrm{~cm} \times 7.5 \mathrm{~cm}$ imitating gastrointestinal stromal tumor (GIST). The patient complained of abdominal pain, nausea and mild anemia. We performed laparoscopic topical excision of the tumor. The postoperative course was uneventful. The 6-month follow-up did not reveal recurrence. The clinical image of a large Vanek's tumor can imitate symptoms of gastric cancer or GIST. Topical laparoscopic excision with a 1-2 cm healthy wall margin is a sufficient and adequate way of treatment.
\end{abstract}

Key words: inflammatory fibroid polyp, Vanek's tumor, cardia, stomach, laparoscopy.

\section{Introduction}

Inflammatory fibroid polyp (IFP) was first described by Vanek over 60 years ago as submucosal granuloma with eosinophilic infiltrations [1]. The lesion is mostly located in the stomach (70\%), small bowel (20\%), rarely in the large bowel and esophagus [2]. Inflammatory fibroid polyps account for approximately $4.5 \%$ of polyps of the stomach [3]. In most cases it is small and can be excised endoscopically; extremely rarely it can reach a large diameter. The symptoms depend on the location and the size of the tumor [4]. Inflammatory fibroid polyp usually is a submucosal tumor (SMT). Large ones can imitate gastric cancer or gastrointestinal stromal tumors (GIST) [5]. The laparoscopic approach is still controversial due to the high risk of tumor rupture or bleeding. Local resection of the stomach is the best method of treatment of SMT [6]. However, it cannot be easily performed laparoscopically on tumors located near the esophagogastric junction.

\section{Case report}

A 67-year-old hypertensive female was admitted to our department with a 6 months history of nausea and discomfort in the upper abdomen. Her medical history included open cholecystectomy, uterine fibroids hysterectomy and right mastectomy for breast cancer. Physical examination revealed a palpable mass in the upper abdomen. Gastroscopy with endoscopic ultrasound showed a protruding oval-shaped submucosal lesion of the anterior body of the stomach, well limited, not infiltrating the gastric wall, with diameter $56 \mathrm{~mm} \times 55 \mathrm{~mm}$. Endoscopic biopsy was negative for neoplastic changes. Ultrasound showed the solid tumor in the left upper abdomen, with diameter $83 \mathrm{~mm} \times 59 \mathrm{~mm}$, and the cyst

\section{Address for correspondence}

Andrzej P. Kwiatkowski MD, PhD, Department of General, Oncological, Metabolic and Thoracic Surgery, Military Institute of Medicine,

128 Szaserów St, 04-141 Warsaw, Poland, phone: +48 791017 093, e-mail: andkwiatkowski@poczta.onet.pl 
of the left lobe of the liver with diameter $14 \mathrm{~mm} \times$ $12 \mathrm{~mm}$. Computed tomography revealed a polycyclic tumor of the minor curvature of the stomach with diameter $93 \mathrm{~mm} \times 68 \mathrm{~mm}$ and a cyst of the left lobe of the liver $(12 \mathrm{~mm})$ and augmented lymph nodes, in the gastro-hepatic ligament $13 \mathrm{~mm}$, in the hilus of the liver $21 \mathrm{~mm} \times 13 \mathrm{~mm}$ and $17 \mathrm{~mm} \times 12 \mathrm{~mm}$ (Photo 1).

Laboratory investigation revealed a hemoglobin value of $10.9 \mathrm{mg} / \mathrm{dl}, \mathrm{MCV} 77 \mathrm{fl}, \mathrm{MCH} 25.4 \mathrm{pg}$. Explorative laparoscopy was performed. We used four trocars, one $12 \mathrm{~mm}$, two $10 \mathrm{~mm}$ and one $5 \mathrm{~mm}$ (Figure 1).

The anterior gastrotomy, done by ultrasound scissors (SonoSurge Olympus), revealed a pediculated tumor of the cardia (Photos 2 and 3 ).

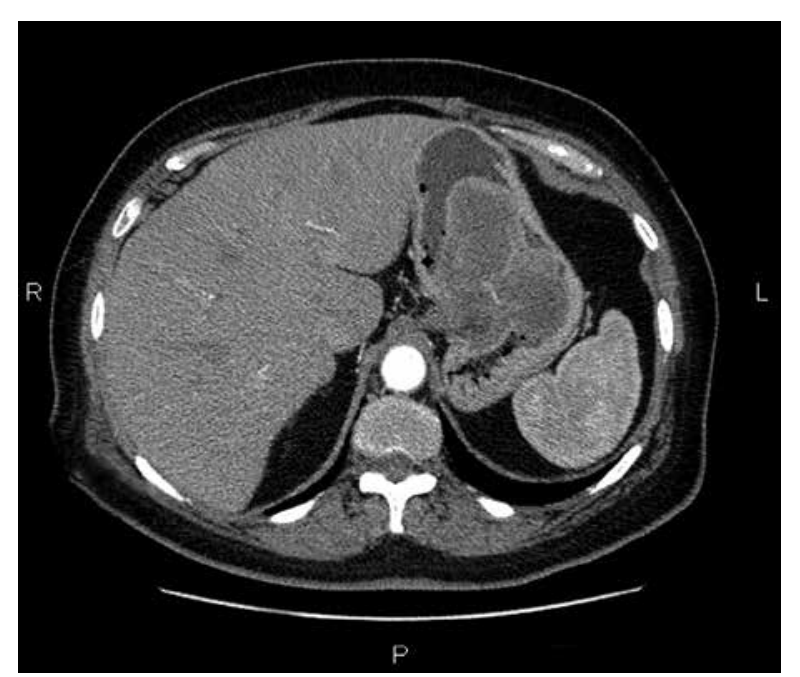

Photo 1. Radiological image of gastric tumor

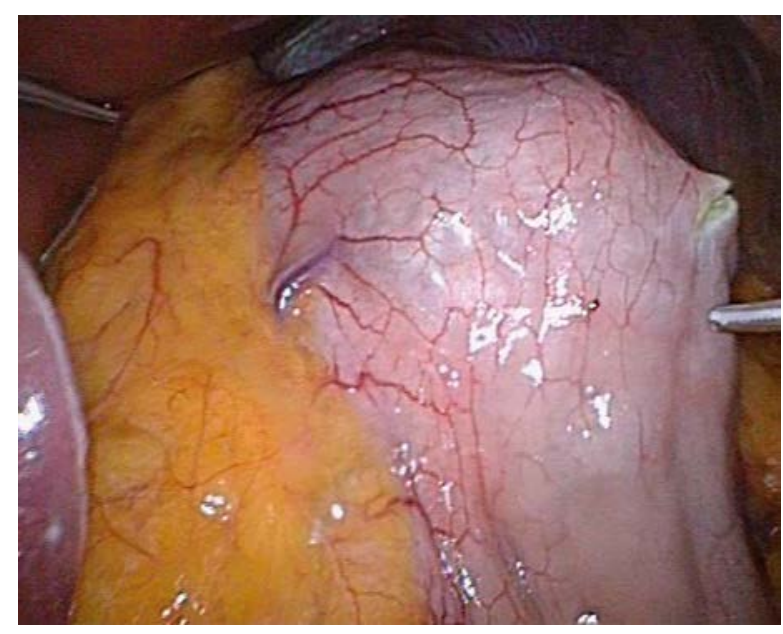

Photo 2. Upper part of stomach before anterior gastrotomy
The posterior wall of the stomach was not explored. The short gastric vessels were not divided. To secure and calibrate the safe passage through the cardia, a $34 \mathrm{Fr}$ gastric tube was inserted through the mouth to the distal part of the stomach. The topical excision was done with two $60 \mathrm{~mm}$ EndoGIA staplers (Tri staple, purple cartridge, Covidien) with a $2 \mathrm{~cm}$ healthy wall margin. The staplers were placed intragastrically. Due to bleeding, the line of resection was reinforced by continuous hand suture. The anterior wall of the stomach was closed with two $60 \mathrm{~mm}$ EndoGIA staplers (Tri staple, purple cartridge,

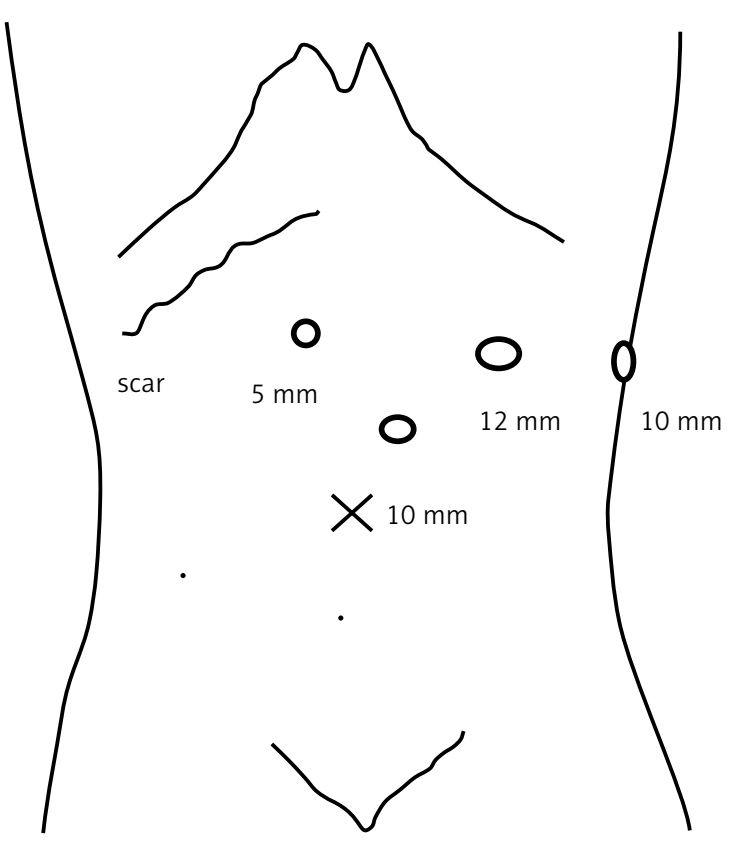

Figure 1. Placement of trocars

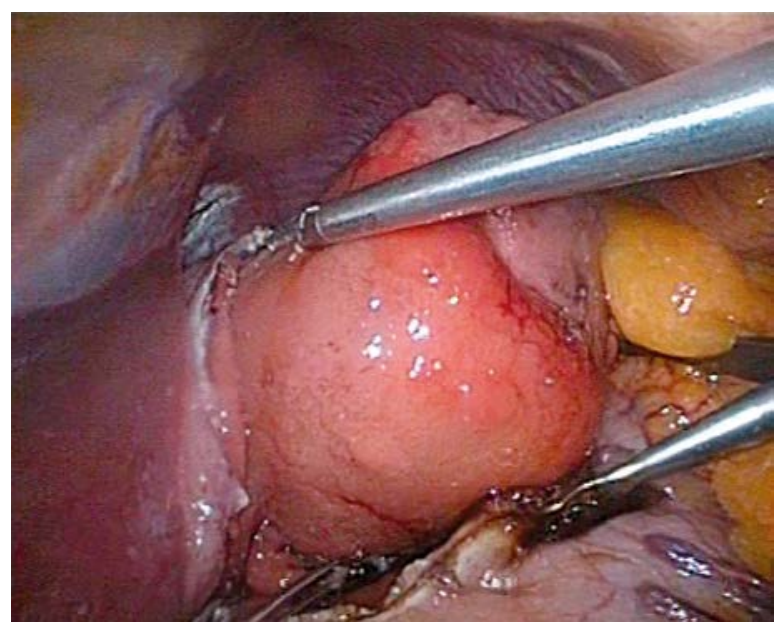

Photo 3. Tumor of cardia after anterior gastrotomy 
Covidien). The staple line was oversewn by external serosal continuous suture. The tumor was extracted through the small incision in the right hypochondrium in the right hypochondrium at the site of scar after open cholecystectomy. Estimated blood loss was about $100 \mathrm{ml}$. The time of operation was $180 \mathrm{~min}$.

The patient made an uneventful postoperative recovery and was discharged 5 days later.

Histological study showed a polypoid lesion of the cardia with a diameter $10 \mathrm{~cm} \times 5.5 \mathrm{~cm} \times 7.5 \mathrm{~cm}$, formed by fibroblastic cells with inflammatory infiltrate of eosinophils and mastocytes. CD 34(+), Vimentin(+), CD117(+) for mastocyte; ALK-1(-); SMA(-); S-100(-); $\mathrm{Bcl}-2(-)$; Synpofizin(-); Ki67(+) were observed in single cells. The diagnosis of IFP was then established. Follow-up gastrofiberoscopy performed 6 and 12 months after surgery showed no signs of any pathology within the site of resection.

\section{Discussion}

Vanek's tumor is currently known as IFP. The name was proposed by Helwig and Ranier in 1953 and now is broadly used and accepted [6].

This tumor has a higher incidence rate in the sixth and seventh decades of life, and it is more often found in women. The lesion can be situated in any part of the gastrointestinal tract, but most often it is located in the antrum of the stomach. Stolte et al. found that $3.1 \%$ of gastric polyps are IFPs [7]. The polyp arises from the submucosa and grows as a polypoid mass [8]. The histological report shows the presence of mononuclear fusiform cells forming extensive bundles or rotary structures of rotated spirals with abundant amounts of eosinophilic cytoplasm. These cells are negatively stained for S-100 protein and desmin and positively for CD-34 [9]. For many years the etiology of the lesion was unknown. There are reports connecting IFP of the stomach with Helicobacter pylori infection [10, 11]. The latest research however revealed mutations of PDGRA in CD-34-positive spindle cells [12]. The mutation types are related to mutations known in GIST. Inflammatory fibroid polyps are true neoplasms, not reactive lesions, and if not completely removed can recur [13].

The clinical manifestations are not specific. Their type and intensity depend on the location and diameter of the lesion. The most common symptoms are gastrointestinal bleeding, unspecified abdominal pain, total or partial intestinal occlusion and intestinal invagination [14]. The localization in the esophagus or in the upper part of the stomach can cause dysphagia and symptoms of gastro-esophageal reflux [15]. Small tumors can be easily removed by an endoscopic approach but after non-radical dissection can recur [16]. Endoscopic biopsy with standard forceps can be misleading when the lesion is covered by normal mucosa [17]. If the IFP reaches a large diameter it often resembles GIST, gastric cancer or leiomyoma [18]. In the case of large tumors we should apply surgical treatment. The laparoscopic approach is still controversial due to the high risk of tumor rupture or bleeding, which can result in peritoneal spreading. But there are reports of successful and safe treatment even of large tumors by the laparoscopic approach [19]. The range of operation depends on the location of the lesion and its diameter but above all depends on the possibility of radical dissection. Local excision, if possible, with an unaltered, healthy wall margin of $1 \mathrm{~cm}$ to $2 \mathrm{~cm}$ is a sufficient, curative way of treatment. The most demanding localization is one near the esophagogastric junction [20]. But even in this case minimal invasive surgery is possible.

\section{Conclusions}

The laparoscopic approach should always be considered in every case of SMT regardless of its size and location.

\section{References}

1. Vanek J. Gastric submucosal granuloma with eosinophillic infiltration. Am J Pathol 1949; 25: 397-411.

2. Blackshaw AJ, Lewsion RA. Eosinophillic infiltrates of the gastrointestinal tract. J Clin Pathol 1986; 39: 1-7.

3. Stolte M, Finkenzeller G. Inflammatory fibroid polyp of the stomach. Endoscopy 1990; 22: 203-7.

4. Galbfach PJ, Narbutt PG, Mik Mt, et al. Inflammatory fibroid polyp of stomach - a case report. Pol Merk Lek 2009; 25: 125-6.

5. Geller AJ, Achem SR, Kolts BE. Giant inflammatory fibroid polyp mimicking gastric cancer. J Clin Gastroenterol 1992; 15: 352-4.

6. Li CJ, Huang MT, Chen CS, et al. Application of laparoscopic techniques for resection of individual gastric submucosal tumors. Surg Laparosc Endosc Percutan Tech 2007; 17: 425-9.

7. Helwig EB, Ranier A. Inflammatory fibroid polyps of stomach. Surg Gunecol Obstet 1953; 96: 355-67.

8. Stolte M, Sticht T, Eidt S, et al. Frequency, location, age and sex distribution of various types of gastric polyp. Endoscopy 1994; 26: 659-65.

9. Adachi Y, Mori M, lida M, et al. Inflammatory fibroid polyp of the stomach. Report of three unusual cases. J Clin Gastroenterol 1992; 15: 154-8. 
10. Kim MK, Higgins J, Cho EY, et al. Expression of CD -34 bcl-2, and kit-inflammatory fibroids polyps of gastrointestinal tract. Appl Immunohistochem Mol Morphol 2000; 8: 147-53.

11. Nishiyama Y, Koyama S, Andoh A, et al. Gastric inflammatory fibroid polyp treated with Helicobacter pylori eradication therapy. Intern Med 2003; 42: 263-7.

12. Shalom A, Wasserman I, Segal M, el al. Inflammatory fibroid polyp and Helicobacter pylori. Aetiology or coincidence? Eur J Surg 2000; 166: 54-7.

13. Schildhaus HU, Buttner R, Binot E. Inflammatory fibroid polyps are true neoplasms with PDGFRA mutations]. Pathologe 2009; 30 Suppl. 2: 117-20.

14. Zinkiewicz K, Zgodziński W, Dabrowski A, et al. Recurrent inflammatory fibroid polyp of cardia: a case report. World J Gastroenterol 2004; 10: 767-8.

15. Leon-Espinoza C, Gomez-Mateo M, Lopez-Mozos F, et al. Does adult intestinal invagination need surgery? Report of case and review of literature. Int J Clin Med 2011; 2: 456-8.

16. Godey SK, Diggory RT. Inflammatory fibroid polyp of the oesophagus. World J Surg Oncology 2005; 3: 30.

17. Matsushita M, Hajiro K, Okazaki K, et al. Endoscopic features of gastric inflammatory fibroid polyps. Am J Gastroenterol 1996; 91: 1595-8.

18. Gutu E, Ghidrin G, Misin I, et al. Bleeding gastric inflammatory fibroid polyp (Vanek's tumor). Chirurgia 2010; 105: 137-40.

19. Gelmini R, Bertolini F, Rossi G, et al. Laparoscopic approach of gastric gastrointestinal stromal tumors (GISTs): is it still a cou rageous choice? Report of two cases. Surg Laparosc Endosc Percutan Tech 2007; 17: 133-7.

20. Morinaga N, Sano A, Katayama K, et al. Laparoscopic transgas tric tumor-everting resection of the gastric submucosal tumor located near the esophagogastric junction. Surg Laparosc Endosc Percutan Tech 2004; 14: 344-8.

Received: 23.06.2013, accepted: 14.09.2014. 